\title{
Can human placental extract help patients with osteoarthritis?
}

\author{
Nequesha S. Mohamed, Wayne A. Wilkie, Ethan A. Remily, Ronald E. Delanois \\ Rubin Institute for Advanced Orthopedics, Center for Joint Preservation and Replacement, Sinai Hospital of Baltimore, Baltimore, MD, USA \\ Correspondence to: Ronald E. Delanois, MD. Rubin Institute for Advanced Orthopedics, Center for Joint Preservation and Replacement, Sinai \\ Hospital of Baltimore, 2401 West Belvedere Avenue, Baltimore, MD, USA. Email: delanois@me.com. \\ Provenance: This is an invited article commissioned by the Editorial Office, Annals of Translational Medicine. \\ Comment on: Gwam C, Ohanele C, Hamby J, et al. Human placental extract: a potential therapeutic in treating osteoarthritis. Ann Transl Med 2019. \\ doi: $10.21037 /$ atm.2019.10.20
}

Submitted Dec 10, 2019. Accepted for publication Dec 16, 2019.

doi: 10.21037/atm.2019.12.135

View this article at: http://dx.doi.org/10.21037/atm.2019.12.135

Osteoarthritis (OA) continues to be a leading cause of disability and healthcare expenditure in the United States (US). This is only expected to rise as the population continues to age (1). Currently, treatment consists of both non-operative and operative techniques. Traditional nonoperative management includes physical therapy, medications, and injections $(2,3)$. Surgical management includes a variety of techniques depending on the extent of cartilage loss. These include but are not limited to microfracture, cartilage replacement, osteotomies, and ultimately total joint arthroplasty $(4,5)$. Despite these successful procedures, many patients prefer to look for alternative methods to avoid undergoing invasive procedures (6). In the past several years, there has been a rise in the use of biologic injections for the treatment of $\mathrm{OA}(2,7)$. Among them are platelet-rich plasma (PRP), stem cells, and now human placental extract (HPE). The overall theory of biologic therapies is to help repair native cartilage through regeneration of chondrocytes or alteration of intracellular signaling pathways $(8,9)$. However, not all of these modalities perform equally, and the article by Gwam et al. in Annals of Translational Medicine reviews the literature surrounding the efficacy of HPE, and its prospective application to $\mathrm{OA}(10)$.

Utilizing HPE to improve OA may be possible due to the nature of this extract. The Gwam study thoroughly explains the purpose of the placenta, and the antiinflammatory factors it possesses which may be able to help regenerate cartilage (10). Although it is traditionally considered a noninflammatory disease, OA still results in some joint inflammation which may be susceptible to the modulatory effect of placental mesenchymal stem cells
(pMSCs) $(2,11,12)$. However, acellular HPE is preferred over pMSCs because of the potential worsening of OA through senescent inactivation of cells (13). Cellular senescence, the inactivation of cellular apoptotic pathways, may be responsible for the inactivation of cellular biologic components typically used to treat OA (14). Thus, arthritic joints may have an accumulation of senescent chondrocytes which secrete inflammatory cytokines, and induce either apoptosis or cell growth arrest in the therapeutic cells, rendering them ineffective $(13,15)$. Acellular HPE circumvents this issue by removing the cellular signaling pathways that senescence targets, retaining the biologically active growth factors, cytokines, and cellular products (16). This advantage is what will likely give HPE an edge in providing effective relief from OA.

The literature documenting the efficacy of HPE for OA is sparse. Although the first studies regarding intra-articular placental extract injections were published in the 1960s, few have updated these initial investigations $(17,18)$. Moreover, much of the current literature on placental extracts for OA and rheumatoid arthritis has been published in Asia. An OA animal model study demonstrated a reduction in joint deformity and decreased histological changes while also exhibiting a protective effect on the remaining cartilage when HPE was administered directly into the joint (19). The results of HPE in a human study demonstrated some success in improving OA symptoms, including pain, swelling, and performance of daily activities (20). Though these studies are few in number, they illustrate the potential utility of HPE in treating OA.

Other biologic therapies have had success in providing 
relief from OA in afflicted patients (2). However, senescence continues to challenge stem cell-based treatments (14). Derived from various lineages including bone marrow, adipose, synovium, and periosteum, stem cells can differentiate into chondrocytes to help repair the damage of OA (21). Unfortunately, they can also undergo stress-induced senescence, and perpetuate the inflammatory environment within the damaged joint (22). Identifying and preventing stem cell senescence has been an ongoing struggle in cartilage regeneration, and has stymied some attempts to regenerate cartilage in native joints (14). Alternatively, PRP, which does not contain cells, has shown more aptitude in not only improving OA symptoms, but also in slowing cellular senescence $(9,14)$. This may be due to the presence of platelet-derived growth factor, which may increase cell proliferation and promote chondrogenesis $(23,24)$. The cytokines and growth factors contained in PRP serum are effective alone, but their effects may be more pronounced with stem cells (9). The same could be reasonably assumed for HPE, as it contains a similar composition of proteins (25). The optimal biologic treatment for OA is likely to be a combination of undifferentiated stem cells which can become healthy chondrocytes, and the appropriate growth factors and cytokines to protect these fragile cells from growth arrest or death.

Utilizing biologic therapies to treat OA has become a popular treatment option for both patients and providers. The current research investigating their efficacy is enlightening, but more trials are needed to determine the best OA treatments, particularly with HPE. Unfortunately, approval from the US Food and Drug Administration (FDA) has restricted what can be offered to treat this disease. Assessing other treatments from around the world may allow a better understanding of the possible avenues through which OA can be halted. The utilization of HPE is one possibility that is most prominent outside of the US, and has been approved by several foreign regulatory agencies for human use. However, it is still unknown whether this extract can effectively treat OA in afflicted patients. Although the literature detailing the advantages and disadvantages of HPE is not yet robust, reviews like the one by Gwam and colleagues are promising foundations for future investigations into the cost and function of HPE in treating OA closer to home.

\section{Acknowledgments}

None.

\section{Footnote}

Conflicts of Interest: Dr. Delanois is a member of the Baltimore City Medical Society, and receives research support from Orthofix, Inc., Stryker, United Orthopedics, Flexion Therapeutics, and TissueGene. The other authors have no conflicts of interest to declare.

Ethical Statement: The authors are accountable for all aspects of the work in ensuring that questions related to the accuracy or integrity of any part of the work are appropriately investigated and resolved.

\section{References}

1. Neogi T, Zhang Y. Epidemiology of OA. Rheum Dis Clin North Am 2013;39:1-19.

2. Delanois RE, Etcheson JI, Sodhi N, et al. Biologic Therapies for the Treatment of Knee Osteoarthritis. J Arthroplasty 2019;34:801-13.

3. Exercise Is Essential for Osteoarthritis: The Many Benefits of Physical Activity. J Orthop Sports Phys Ther 2018;48:448.

4. de l'Escalopier N, Anract P, Biau D. Surgical treatments for osteoarthritis. Annals of Physical and Rehabilitation Medicine 2016;59:227-33.

5. Taruc-Uy RL1, Lynch SA. Diagnosis and Treatment of Osteoarthritis. Prim Care 2013;40:821-36, vii.

6. Mounsey A, Ewigman B, Hickner J. Arthroscopic surgery for knee osteoarthritis? Just say no. Journal of Family Practice 2009;58:143-5.

7. Raynauld JP, Buckland-Wright C, Ward R, et al. Safety and efficacy of long-term intraarticular steroid injections in osteoarthritis of the knee. Arthritis Rheum 2003;48:370-7.

8. McGonagle D, Baboolal TG, Jones E. Native jointresident mesenchymal stem cells for cartilage repair in osteoarthritis. Nat Rev Rheumatol 2017;13:719-30.

9. Ornetti P, Nourissat G, Berenbaum F, et al. Does plateletrich plasma have a role in the treatment of osteoarthritis? Joint Bone Spine 2016;83:31-6.

10. Gwam C, Ohanele C, Hamby J, et al. Human placental extract: a potential therapeutic in treating osteoarthritis. Ann Transl Med 2019. doi:10.21037/atm.2019.10.20

11. Goldring MB, Otero M. Inflammation in osteoarthritis. Current Opinion in Rheumatology 2011;23:471-8.

12. Choi JH, Jung J, Na KH, et al. Effect of mesenchymal stem cells and extracts derived from the placenta on 
trophoblast invasion and immune responses. Stem Cells Dev 2014;23:132-45.

13. Cao X, Luo P, Huang J, et al. Intraarticular senescent chondrocytes impair the cartilage regeneration capacity of mesenchymal stem cells. Stem Cell Res Ther 2019;10:86.

14. Li J, Pei M. Cell senescence: a challenge in cartilage engineering and regeneration. Tissue Eng Part B Rev 2012;18:270-87.

15. Endrinaldi E, Darwin E, Zubir N, et al. The Effect of Mesenchymal Stem Cell Wharton's Jelly on Matrix Metalloproteinase-1 and Interleukin-4 Levels in Osteoarthritis Rat Model. Open access Maced J Med Sci 2019;7:529-35.

16. Pan SY, Chan MK, Wong MB, et al. Placental therapy: An insight to their biological and therapeutic properties. J Med Ther 2017. doi:10.15761/jmt.1000118.

17. Verhaeghe A, Lebeurre R, Lesage R, et al. 1st rhematological trials of intra-articular injections of placental extracts. Lille Med 1961;6:244-5.

18. Livingston WS, Compton EL. The Livingston placental autolysate: effect upon rheumatoid and osteoarthritis. Rocky Mt Med J 1967;64:73-9.

19. Kim JK, Kim TH, Park SW, et al. Protective effects of human placenta extract on cartilage degradation

Cite this article as: Mohamed NS, Wilkie WA, Remily EA, Delanois RE. Can human placental extract help patients with osteoarthritis? Ann Transl Med 2020;8(4):62. doi: 10.21037/ atm.2019.12.135 in experimental osteoarthritis. Biol Pharm Bull 2010;33:1004-10.

20. Park KM, Cho TH. Therapeutic effect of acupuncture point injection with placental extract in knee osteoarthritis. J Integr Med 2017;15:135-41.

21. Macrin D, Joseph JP, Pillai AA, et al. Eminent Sources of Adult Mesenchymal Stem Cells and Their Therapeutic Imminence. Stem Cell Rev Rep 2017;13:741-56.

22. Tchkonia T, Morbeck DE, Von Zglinicki T, et al. Fat tissue, aging, and cellular senescence. Aging Cell 2010;9:667-84.

23. Drengk A, Zapf A, Stürmer EK, et al. Influence of platelet-rich plasma on chondrogenic differentiation and proliferation of chondrocytes and mesenchymal stem cells. Cells Tissues Organs 2009;189:317-26.

24. Mishra A, Tummala P, King A, et al. Buffered platelet-rich plasma enhances mesenchymal stem cell proliferation and chondrogenic differentiation. Tissue Eng Part C Methods 2009; 15:431-5.

25. Choi JS, Kim JD, Yoon HS, et al. Full-thickness skin wound healing using human placenta-derived extracellular matrix containing bioactive molecules. Tissue Eng Part A 2013;19:329-39. 